\title{
STRATEGI PEMASARAN PAKET WISATA PADA PT. CAHAYA TEDUNG ABADI HOLIDAY DENPASAR
}

\author{
Putu Doddy Pramana \\ Ni Made Oka Karini \\ I Putu Sudana \\ Email : putudoddypramana@yahoo.com \\ PS. S1 Industri Perjalanan Wisata \\ Fakultas Pariwisata UNUD
}

\begin{abstract}
PT. Cahaya Tedung Abadi Holiday is a business that handles tour ticket sales, travel documents, tour guide services, hotel reservation and sales of tour packages. To anticipate the traveler visits that always fluctuated and competition with other travel agency, need to be design tour package marketing strategy. So PT. Cahaya Tedung Abadi Holiday can optimize the strength, opportunities, and minimize the weaknesses and threats.

The goal is to find alternative are strategies and programs that can be implemented by PT. Cahaya Tedung Abadi Holiday in selling tour package. Data collection techniques using the method of observation, in-depth interviews, library research and documentation. Researchers used a key informant Mr. I Gusti Sudarsana, two employees and sales marketing products as an informant base. This research is a descriptive qualitative with Matrix SWOT approach and the marketing mix.

Alternative strategies that can be implemented by PT. Cahaya Tedung Abadi Holiday are : (a) create and develop tourism products strategy by creating new innovative tourism products and a special interest tour packages, (b) market segmentation strategy development with opportunities to develop a broader market, (c) increased promotion strategy by advertising, brochures and collaboration with TV channel with tourism programs information, (d) improve the quality of products and services strategies by redesigning the tour packages program more interesting in order the tourists interested to buy tour packages, maintaining cleanliness and tidiness of the vehicle and driver guides during tours and reemphasize tourism products according to the company market share.

The suggestion for the company to expand its market share in order to survive the competition of other travel agencies, companies should increase the workforce to be more rapid and responsive in accepting tour packages purchases and fixed preserve good relations with related companies such as the hotel, restaurant, overseas agent, transport and tourism destination managers.
\end{abstract}

Keywords: Marketing Strategy, Tour Packages.

\section{PENDAHULUAN}

Bali merupakan salah satu daerah yang ada di Indonesia yang mempunyai potensi yang besar dalam kepariwisataan. Bali tidak bisa terlepas dari keindahan alam dan beragam akan budaya yang menarik dan sudah terkenal di kalangan mancanegara. Sejalan dengan perkembangan tersebut Bali telah mampu menempatkan posisinya sebagai daerah tujuan wisata yang memiliki daya tarik tersendiri dan tidak terlepas dari peran industri pariwisata yang bertugas untuk penyedia sarana dan prasarana yang terlihat pada (something to see) sesuatu yang dapat dilihat (something to buy) sesuatu yang dapat dibeli dan (something to do) sesuatu yang dapat dilakukan. Seperti halnya industri jasa pariwisata yaitu biro perjalanan wisata yang bertindak sebagai penghubung antara konsumen dengan pihak penyedia jasa seperti hotel, restoran, destinasi wisata dan transportasi.

Salah satu biro perjalanan wisata di Bali yaitu PT. Cahaya Tedung Abadi Holiday merupakan usaha biro perjalanan wisata yang menangani penjualan tiket pesawat, dokumen perjalanan, tour guide service, reservasi hotel 
dan penjualan paket wisata. Terlihat dari jumlah kunjungan wisatawan yang mengalami fluktuasi, dan banyaknya jumlah biro perjalanan wisata lainnya dengan tingkat persaingan yang tinggi, maka diperlukan sebuah strategi pemasaran untuk mengantisipasi hal tersebut dalam menjual paket wisata kepada wisatawan agar PT. Cahaya Tedung Abadi Holiday dapat mengoptimalkan sebuah kekuatan dan peluang yang ada serta meminimalkan kelemahan dan ancaman di dalam memasarkan paket wisatanya. Dari ulasan-ulasan diatas maka penulis bermaksud untuk melakukan penelitian dengan mengangkat permasalahan mengenai strategi pemasaran paket wisata pada PT. Cahaya Tedung Abadi Holiday Denpasar.

\section{TINJAUAN PUSTAKA}

Menurut Jhonson and Scholas (dalam Purwanto, 2012) strategi adalah suatu arah dan cakupan organisasi yang terbaik untuk masa yang lebih panjang dan menyesuaikan sumber daya dengan perubahan lingkungan pasarya kepada pelanggan dan kliennya demi memenuhi harapan dari stakeholder.

Pemasaran menurut Daryanto (2011) adalah suatu gejala sosial dimana dari individu dan kelompok berkeinginan untuk mendapatkan sesuatu yang mereka inginkan seperti dengan caramenawar dan menciptakan sesuatu yang bernilai tinggi satu dengan yang lainnya.

Menurut Budi (2013) bauran pemasaran adalah suatu alat bagi pemasar yang mempunyai unsur program pemasaran agar dapat implementasi serta perlu adanya sebuah pertimbangkan di dalam menetapkan strategi pemasaran dan positioning yang digunakan dapat berjalan secara lancar.

Menurut Yoeti (2003) paket wisata adalah suatu rancangan atau susunan dari komponen wisata yang dibuat oleh biro perjalanan wisata yang meliputi destinasi wisata, hotel, restoran, transportasi dan sebagainya.

Menurut Yoeti (2003) biro perjalanan wisata adalah suatu perusahaan yang menekankan pada perencanaan, penyelanggaraan perjalanan wisata atas keinginan sendiri dan tanggung jawab sendiri dengan tujuan demi mendapatkan keuntungan.

\section{METODE PENELITIAN}

Penelitian ini dilakukan pada PT. Cahaya Tedung Abadi Holiday, yang berlokasi di J1. Griya Anyar No. 90 Denpasar, Bali. Adapun teknik yang akan digunakan dalam penelitian ini yaitu teknik pengumpulan data menggunakan teknik observasi, wawancara mendalam, studi kepustakaan serta dokumentasi seperti foto-foto dan gambar yang mendukung kegiatan penelitian.

Teknik penentuan informan pada penelitian ini menggunakan informan kunci adalah Bapak I Gusti Sudarsana selaku owner dan informan pangkal adalah tiga karyawan sales marketing, reservasi dan product yang bekerja di PT. Cahaya Tedung Abadi Holiday yang terkait pada strategi pemasaran diperusahaan tersebut.

Pada penelitian ini merupakan penelitian deskriptif kualitatif yaitu dengan menggunakan pendekatan analisis Matrik SWOT dan kondisi bauran pemasaran (marketing mix 7P). Suatu perusahaan harus bisa mempertimbangkan kekuatan dan kelemahan perusahaan terhadap peluang dan ancaman lingkungan.

\section{HASIL DAN PEMBAHASAN \\ Unsur-unsur Strategi Pemasaran PT. Cahaya Tedung Abadi Holiday}

1. Segmentasi Pasar (Segmenting) adalah mengidentifikasi dan membentuk kelompok pasar. Adapun segmentasi pasar dari PT. Cahaya Tedung Abadi Holiday adalah kebanyakan wisatawan domestik, karena dari pangsa pasar domestik setidaknya dapat meminimalkan ancaman dari luar seperti travel warning.

2. Penentuan Pasar (Targeting) adalah tindakan memilih satu atau lebih segmen pasar. Adapun targeting dari PT. Cahaya Tedung Abadi Holiday adalah sasaranya berdasarkan letak geografis dan daya beli dari pasar yang ada. Berdasarkan segmentasi pasar domestik, maka target pasarnya adalah Makassar, Bandung, Jakarta, Jogyakarta dan daerah Irianjaya.

3. Penentuan Posisi Pasar (Positioning) adalah penetapan posisi pasar dengan tujuan membangun komunikasi dalam keunggulan bersaing produk yang akan dipasarkan. Adapun positioning dari PT. Cahaya Tedung Abadi Holiday adalah terkadang memberikan biro perjalanan 
wisata yang diajak kerjasama dengan PT. Cahaya Tedung Abadi Holiday potongan harga kamar dan tour pada saat inpection atau kunjungan ke Bali, karena dengan kegiatan tersebut dapat menjadi kekuatan dan peluang untuk mempererat hubungan kerjasama di bidang biro perjalanan wisata.

\section{Analisis Bauran Pemasaran (Marketing Mix 7P)}

Produk (product) adapun paket wisata yang dimiliki adalah: Kintamani Tours, Bedugul Tours dan Nusa Dua Tours. Harga (price) untuk harga paket wisata tour ditetapkan dengan mata uang rupiah, dengan mempertimbangkan biaya operasional dan sudah termasuk harga hotel, paket wisata, transportasi serta tiket pesawat udara dan diluar dari pengeluaran pribadi. Saluran distribusi (place) pada PT. Cahaya Tedung Abadi Holiday adalah dengan menyalurkan paket wisatanya secara langsung (terkadang konsumen secara langsung membeli paket wisata, karena ingin berlibur ke Bali dengan keluarga) dan tidak langsung (biro perjalanan wisata di luar Bali membeli paket wisata dengan PT. Cahaya Tedung Abadi Holiday). Promosi (promotion) yang dilakukan dengan melalui brosur yang ditaruh di bandara dan melalui media sosial seperti facebook, website dan melalui biro perjalanan wisata di luar Bali yang sudah diajak bekerjasama. Orang (people) PT. Cahaya Tedung Abadi Holiday memiliki tiga karyawan yaitu bagian sales marketing, bagian reservasi dan bagian produk. Lingkungan fisik (physical evidence) bukti fisik yang mendukung kualiats pelayanan pada PT. Cahaya Tedung Abadi Holiday yaitu: adanya gedung perusahaan, komputer yang digunakan dalam proses menerima pembelian paket wisata, seragam perusahaan dan transpotasi yang mendukuang dalam kegiatan tour. Proses (process). Adapun proses yang dilakukan oleh sales marketing pada PT. Cahaya Tedung Abadi Holiday untuk memasarkan produk wisatanya dengan cara melakukan sales promotion ke biro perjalanan wisata di luar Bali agar dapat memperluas targeting yang sudah dimiliki sebelumnya.

\section{Strategi Pemasaran yang harus diterapkan pada PT. Cahaya Tedung Abadi Holiday}

Pada bagian ini membahas tentang analisis Matrik SWOT sebagai kekuatan, kelemahan, peluang dan ancaman yang dimiliki pada PT. Cahaya Tedung Abadi Holiday yang berhubungan dengan bauran pemasaran (marketing mix). Adapun Tabel analisis Matrik SWOT pada PT. Cahaya Tedung Abadi Holiday dapat dilihat pada Tabel 1.

Tabel 1. Analisis Matrik SWOT

PT. Cahaya Tedung Abadi Holiday

\begin{tabular}{|c|c|c|}
\hline IFAS & $\begin{array}{l}\text { Kekuatan }(\boldsymbol{S}) \\
\text { 1. Produk wisata beragam dan inovatif. } \\
\text { 2. Penyampaian informasi paket wisata dari guide } \\
\text { ke wisatawan. } \\
\text { 3. Kebersihan dan kenyamanan transportasi saat } \\
\text { melakukan tour. } \\
\text { 4. Kemampuan berbahasa guide dalam melayani } \\
\text { wisatawan. } \\
\text { 5. Pemandu yang ramah dalam memberikan } \\
\text { informasi kepada wisatawan. }\end{array}$ & $\begin{array}{l}\text { Kelemahan }(\boldsymbol{W}) \\
\text { 1. Produk wisata kebanyakan dipesan oleh } \\
\text { wisatawan domestik. } \\
\text { 2. Kurangnya armada transportasi dalam } \\
\text { pelayanan tour. } \\
\text { 3. Penyajian paket wisata dalam bentuk brosur } \\
\text { atau majalah. }\end{array}$ \\
\hline \multicolumn{3}{|l|}{ EFAS } \\
\hline $\begin{array}{l}\text { Peluang }(\boldsymbol{O}) \\
\text { a. Perkembangan alat komunikasi. } \\
\text { b. Kemajuan media internet dalam memasarkan } \\
\text { jasa. } \\
\text { c. Pariwisata Bali yang berbasis budaya. } \\
\text { d. Budaya masyarakat Bali di dalam } \\
\text { mendukung kegiatan pariwisata. }\end{array}$ & $\begin{array}{l}\text { Strategi }(\mathbf{S O}) \\
\text { Strategi penciptaan dan pengembangan produk } \\
\text { wisata : } \\
\text { (Kombinasi antara } 1,2,3,4,5 \text { dan a,b,c,d). }\end{array}$ & \begin{tabular}{l}
\multicolumn{1}{c}{ Strategi $(\boldsymbol{W O})$} \\
Strategi peningkatan promosi : \\
(Kombinasi antara $1,2,3$ dan a,b).
\end{tabular} \\
\hline $\begin{array}{l}\text { a. Pesatnya perkembangan biro perjalanan } \\
\text { wisata. } \\
\text { b. Kemacetan lalu lintas yang tidak terkendali. } \\
\text { c. Krisis ekonomi global. } \\
\text { d. Kenaikan harga BBM. } \\
\text { e. Tingkat bencana alam sulit diprediksi. }\end{array}$ & $\begin{array}{l}\text { Strategi }(\boldsymbol{S T}) \\
\text { Strategi pengembangan segmentasi pasar : } \\
\text { (kombinasi antara } 1,2,3,4,5 \text { dan a,b,c,d,e) }\end{array}$ & $\begin{array}{l}\text { Strategi }(\boldsymbol{W T}) \\
\text { Strategi peningkatan kualitas produk dan jasa : } \\
\text { (Kombinasi antara } 1,2 \text { dan a,b,c,d) }\end{array}$ \\
\hline
\end{tabular}


Terlihat dari Tabel analisis Matrik SWOT dapat dijelaskan strategi pemasaran yang sebaiknya diterapkan pada PT. Cahaya Tedung Abadi Holiday sebagai berikut :

Strategi SO :

Strategi yang memanfaatkan kekuatan atas peluang yang telah diidentifikasi. Strategi yang dapat diterapkan dalam memasarkan peket wisata pada PT. Cahaya Tedung Abadi Holiday adalah strategi penciptaan dan pengembangan produk wisata.

\section{Strategi ST}

Strategi ini menggunakan kekuatan yang dimiliki perusahaan untuk mengatasi ancaman. Strategi yang dapat diterapkan dalam pemasaran pada PT. Cahaya Tedung Abadi Holiday adalah strategi pengembangan segmentasi pasar.

\section{Strategi WO}

Strategi ini diterapkan berdasarkan pemanfaatan peluang yang ada dengan cara meminimalkan kelemahan yang ada. Strategi yang dapat diterapkan pada PT. Cahaya Tedung Abadi Holiday adalah strategi peningkatan promosi.

\section{Strategi WT}

Strategi ini bertujuan untuk bertahan dengan meminimalisir kelemahan dengan menghindari ancaman. Strategi yang dapat diterapkan pada PT. Cahaya Tedung Abadi Holiday adalah strategi peningkatan kualitas produk dan jasa

\section{SIMPULAN DAN SARAN Simpulan}

Hasil dari pembahasan mengenai strategi pemasaran pada PT. Cahaya Tedung Abadi Holiday berdasarkan analisis Matrik SWOT, yaitu menganalisis kekuatan (Strenghts), kelemahan (Weaknesses), peluang (Opportunities) dan ancaman (Threats) terhadap unsur-unsur bauran pemasaran (marketing mix 7P) serta pemasaran paket wisata pada PT. Cahaya Tedung Abadi Holiday. Adapun program bauran pemasaran yang dapat diterapkan pada PT. Cahaya Tedung Abadi Holiday sebagai berikut :

1. Menciptakan produk wisata yang baru dan inovatif, yaitu pengemasan paket wisata yang belum pernah dipasarkan oleh biro perjalanan lainnya.

2. Membuat paket wisata minat khusus yang bertujuan memberikan sesuatu yang baru kepada wisatawan.
3. Membuka dan mengembangkan peluang pasar yang lebih luas.

4. Produk wisata yang sudah ada digabungkan dengan produk wisata baru yang dibutuhkan oleh konsumen.

5. Promosi melalui iklan dengan bentuk brosur atau majalah dan bekerjasama dengan TV Channel melalui program tourism and information.

6. Pihak sales marketing harus menjalin hubungan dengan overseas agent dari luar untuk mempromosikan paket wisata yang dimilikinya.

7. Mendesain ulang paket wisata yang sudah dimiliki agar menarik minat wisatawan untuk membeli paket wisata yang dijual.

8. Menjaga kebersihan kendaraan dan kerapian guide serta sopir selama melakukan tour dengan wisatawan.

9. Mengganti nama produk wisata dengan ciri khas bahasa dari pangsa pasar perusahaan, agar dapat menambah minat wisatawan, namun tetap mempertahankan itensitas paket wisata agar tidak berubah dan tetap konsisten.

\section{Saran}

Berdasarkan hasil dan pembahasan yang telah dibuat, adapun saran-saran yang dianggap perlu dan penting untuk kemajuan pada PT. Cahaya Tedung Abadi Holiday untuk dimasa yang akan datang seperti :

1. Perusahaan sebaiknya memperluas pangsa pasar agar tetap bisa bertahan dari persaingan dengan biro perjalanan wisata lainnya di Bali.

2. Perusahaan sebaiknya menambah tenaga kerja atau karyawan, agar bisa lebih cepat dan tanggap jika ada pembelian paket wisata dari wisatawan

3. Perusahaan perlu me-update alat promosi seperti website dan menambah informasi mengenai paket-paket wisata yang dimiliki oleh perusahaan, baik itu paket yang spesial dan paket wisata unggulan serta rute-rute perjalanan di dalam paket wisata yang dijual oleh perusahaan.

4. Tetap menjaga hubungan baik dengan perusahaan yang terkait dengan perusahaan dan dalam penjualan paket wisata kepada wisatawan seperti diantaranya pihak hotel, restoran, overseas agent, transportasi dan pengelola destinasi wisata. 
Jurnal IPTA

ISSN : 2338-8633

Vol. 2 No. 2, 2014

\section{DAFTAR PUSTAKA}

Budi, Agung Permana. 2013. Manajemen Marketing Perhotelan. Yogyakarta : CV Andi Offset.

Daryanto. 2011. Sari Kuliah Manajemen Pemasaran. Bandung : PT. Sarana Tutorial Nurani Sejahtera.

Purwanto, Drs. 2012. Marketing Strategic Meningkatkan Pangsa Pasar \& Daya Saing. Jakarta : Platinum.

Yoeti, Drs. Oka A. 2003. Tours and Travel Marketing. Jakarta :PT. Pradnya Paramita. 